\title{
Interactive comment on "From fibrous plant residues to mineral-associated organic carbon - the fate of organic matter in Arctic permafrost soils” by Isabel Prater et al.
}

\section{Anonymous Referee \#2}

Received and published: 20 March 2020

The manuscript entitled "From fibrous plant residues to mineral-associated organic carbon - the fate of organic matter in Arctic permafrost soils" analysed four Cryosol soil cores for quantity and quality of organic matter to understand stabilization mechanisms and mineralization potential under climate change. The manuscript is very well written, within the scope of Biogeosciences and informative. No major methodological flaws were detected. The novelty of the results is somewhat limited, the results are close to what should have been expected. However, every new dataset on soils from these remote land masses that are warming up rapidly is valuable per se and the mix of methods is strong, of course. My most important major concern is that I was not able to understand how the authors exactly did the $1 \mathrm{~m}$ stock extrapolation when only some

Printer-friendly version

Discussion paper 
selected layers were fractionated. There is no information on that specific issue and looking at the reference publication reveals that soil profiles (usual for river terraces) were extremely heterogeneous with depth. This depth dependency and spatial heterogeneity in general, is of major importance for upscaling, which is again of specific importance for that vast and SOC rich region. This starts from how single soil profiles are averaged which should thus be done and described with care. A second major issue is related to the data shown in Fig. 4a: How do the authors explain this positive correlation of $\mathrm{d} 13 \mathrm{C}$ and $\mathrm{C} / \mathrm{N}$ ratio within the fractions, I think the opposite would be expected (the more decomposed, the more positive d13C)? Still, my recommendation is publish after some revisions. Please find specific comments below:

General: You might want to consider to call oPOM oPOMl (I for large), this would be more consistent when you also have oPOMs as individual fraction.

I.16: "the permafrost region" appears too unspecific. Is it the Northern Circumpolar Permafrost region or do you include the high mountain ranges here?

I.74: Why Ping et al. at the end?

1.94-97: Please be more specific about the sapling locations, or the selection of these 4 cores. Why those, any criteria to ensure that they are representative for the most likely very heterogeneous area? Can't really find information on that in the cited literature. Also, please mention the soil types. In Zubrzycki et al.2013, different soil types are mentioned. Was it all cryoturbated soils?

I.102: Which selected layers, how many samples were fractionated?

I.102: Table 1 is missing, but would be extremely important, also to judge about some interpretations of the authors.

Printer-friendly version

I.117: During the washing... $\rightarrow$ How did you separate MAOM and oPOMs? Another density step? This is not clear.

Discussion paper

I.126: Projected to $1 \mathrm{~m}$ : How was this done exactly, and why is there no information 
about the depth distribution of fractions if the authors state that different depths were analysed? This is a bit confusing.

I.164: find correlations with what?

I.188: give ranges for the silt and sand-sized MAOM as well, otherwise the sentence reads incomplete.

Interactive

comment

I.217: This is something that is not clear to me: How do you explain this trend? Usually it should be the other way around. Why is $\mathrm{d} 13 \mathrm{C}$ more negative when $\mathrm{C} / \mathrm{N}$ ratios are decreasing?

Results in general: I was missing a depth distribution of the fractions, all results are depth independent and it is unclear, how homogeneous the profiles were.

I.268: It is not clear to me, if really cryoturbation caused the depth distribution of POM, but again this can only be judged if some depth information is included. Especially in river terraces, it could also be successive growth of the soil profile via sedimentation, and potentially even growth of organic layers.

I.286: Title sounds like POM fractions do also dominate $\mathrm{N}$ stocks, which doesn't seem to be the case (table 1). Maybe consider to rephrase.

I.293: "release vasts amount of N" $\rightarrow$ This is a contradiction to what has been said before and also the title (not much $\mathrm{N}$ in POM fractions)

I.313: Where does this information come from that fibres act as hot spots for microbial decay?

I.356: Where is this comparison per single soil layers?

Fig.4: X-axis: Why did you put the x-axis on top of the graph and show only 10 and 100 ? Is there any reason for that. Readability would improve when numbers are at the bottom and more continuous.

Printer-friendly version

Discussion paper 
Interactive comment on Biogeosciences Discuss., https://doi.org/10.5194/bg-2020-52, 2020.

Interactive

comment 